\title{
Dentistry's 'me too'
}

moment?

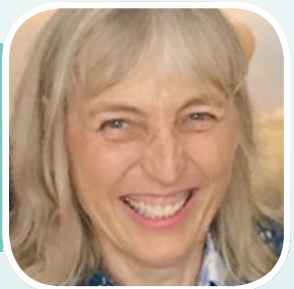

Caroline Holland argues that equality, solidarity and humanity should be factored into dentistry's most topical debate.

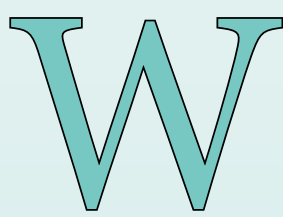

hen, in the space of just one hour in February, hundreds of hygienists and therapists commented angrily on an article placed on a private forum, it felt as if the dental profession was having its own 'me too' moment.

The trigger was an article entitled: Can a hygienist work without a dental nurse? The article was seen to endorse the practice of hygienists and therapists working single-handed. The reference to a hygienist being 'an asset' to their practice when they worked without assistance was met with outrage.

What went unacknowledged was how hard it might be for the hygienist to be that 'asset.' Two articles in our April issue depict lucidly what it's like to be a hygienist/therapist working on their own. BDJ Team is also publishing an article by dento-legal consultant Sue Boynton. She emphasises the decision-making responsibility of all dental registrants.

And this is where we reach the heart of the matter. All dental registrants have a professional duty to ensure they practise safely - but not all dental registrants feel like they have the freedom to choose. Hygienists/therapists are largely employed or self-employed working in practices owned by dentists or dental corporates who decide on staffing levels.

Some practice owners, encouraged by accountants and business consultants, have bracketed hygienists as 'profit centres.' 'Get your hygienist a full book and develop an income stream, has been the mantra. Dental consultant Sheila Scott was not among these advisors. She not only believes in the role of the hygienist, she argues strongly that all clinicians need support. Practices which are dedicated to the interests of patients are often the practices which thrive, she says.
Whenever the topic of singlehanded working has come up for discussion in recent weeks, I have been told this is an economic issue. But is this completely true? When I interviewed Debbie McGovern, the President of the British Association of Dental Therapists - https://www.nature.com/ articles/bdjteam201941 - I learned that in the practices she co-owns with her dentist husband, all therapists have a dental nurse working alongside them, including when they are delivering hygiene treatments. The risk assessments the McGoverns undertook reached the conclusion that this is the best and safest way

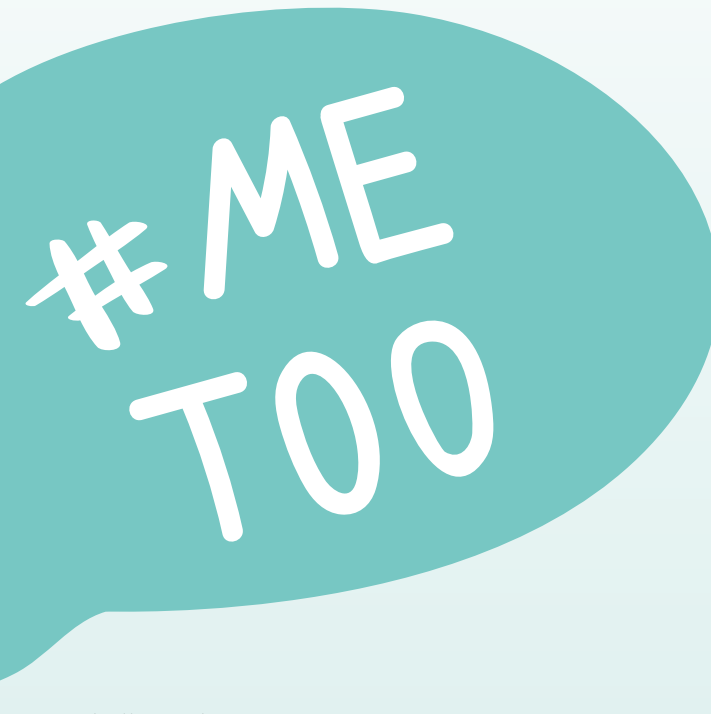

unchallenged.

The practice of hygienists and therapists working single-handed is sustained by a system in which one group of clinicians has mostly held the contracts, the purse-strings and by default, the power. It's not helped by GDC guidance which puts the onus on each individual clinician to decide on the best course of action. A spokesperson for the GDC told BDJ Team:

'When providing treatment, dental professionals need to work together in the best interests of patients, and this includes working with appropriate support from other members of the dental team. As the regulator, we do not

\section{'ALL DENTAL REGISTRANTS HAVE A PROFESSIONAL}

\section{DUTY TO ENSURE THEY PRACTISE SAFELY - BUT}

\section{NOT ALL DENTAL REGISTRANTS FEEL LIKE THEY}

\section{HAVE THE FREEDOM TO CHOOSE.'}

to practise. There are other practices which share this view and provide a dental nurse for their hygienist/therapist, so the argument that this is an economic issue does not apply universally.

If this is such a critical issue, it's argued, why haven't dentists and therapists and their representative organisations done more to change the status quo? In the wake of the 'me too' movement, who would have dared put that question to the hundreds of actresses who risked assault or humiliation when they pitched for a part in a Harvey Weinstein film? A powerful movie moghul, his behaviour was knowingly upheld by a whole industry of people and, until the 'me too' movement, which became the tipping point, his 'approach' to casting went prescribe what form that support should take, and it is for the individual to apply their professional judgement to assess the level and type of support that is appropriate. As always, dental professionals need to engage with the Standards to guide them in their work.'

We all agree that the GDS contract needs to change - but perhaps the profession needs to change too. A tipping point may have been been reached, driven by an impetus for equality and solidarity. And a bit of humanity towards colleagues who often work in isolation would not go amiss either. 